
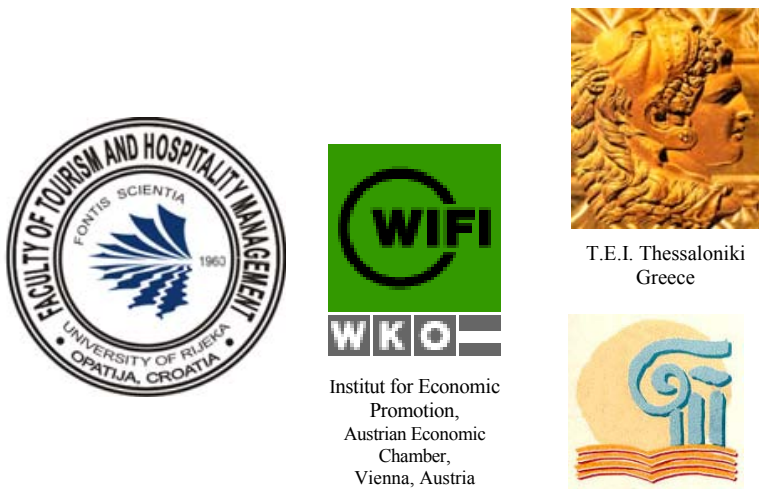

\title{
DEVELOPING HUMAN RESOURCES' SKILLS AND KNOWLEDGE IN TOURISM AND HOSPITALITY INDUSTRY THROUGH THE DETERMINATION OF QUALITY OF TRAINING PROGRAMS
}

\author{
Ioannis Valachis \\ Evaggelos Christou \\ Marianna Sigala \\ Leonidas Maroudas
}

University of The Aegean, Chios, Greece ${ }^{1}$

\begin{abstract}
Research into tourism and hospitality training field has been focused on the subjects of training need assessments, training evaluation models, training within organizational frameworks and useful training techniques. Despite the significance of the above aspects, less afford has been made in the field of training quality and particularly in defining those factors that the quality of a training program consists of.

Taking into account that training is a service which the organization, the producer, delivers to its employee, the consumer, this research is going one step further and not only exams SERVQUAL in the training field, but tries to examine inductively at distinctive training quality dimensions from the perspective of trainees point of view that are not subject of other service industry. The definition of training quality dimensions can lead those who develop a new training program to use those dimensions as a framework for greater training outcomes. Moreover, this research tests how the GAP model is compared with the measurement of perceptions merely and the measurement of expectations lone of training quality, as defined by the trainees.
\end{abstract}

Key words: hospitality and tourism industry, GAP model, training program quality dimensions, SERVQUAL.

\footnotetext{
${ }^{1}$ Ioannis Valachis, Evaggelos Christou, Marianna Sigala, Leonidas Maroudas, University of The Aegean, Chios, Greece.
} 
Tourism and Hospitality Management, Vol. 15, No. 1, pp. 61-72, 2009

I. Valachis, E. Christou, M. Sigala, L. Maroudas: DEVELOPING HUMAN RESOURCES' SKILLS ...

\section{INTRODUCTION}

The purpose of this article is to describe the development of a training quality measurement scale, and presents the scale's properties and potential applications. According to Alliger, Tannenaum, Bennett, Traver, and Shotland (1997) and Kirkpatrik (1998), employees are the customers of training. As a result, this research tries to find resources and theories through several of fields of study such as quality of services, human resource development, hospitality and tourism management education and training and organisational behaviour.

In this research figured out which are the dimensions that determine the trainees' perceptions regarding training quality and how the GAP model compared with the perceptions and the expectations measurement, individually, which synthesize the GAP model of training quality, as defined by the trainees' perceptions. Furthermore, the research revealed relationships between training quality, as defined by trainees, and an intention of those trainees to transfer their knowledge gained on the training class to their jobs. Consistent with Kirkpatrik (1959), these reaction measures deal with trainees' attitudes regarding their opinion for a training program.

Although Eddie, Cheng, and Danny (2004) and Alliger, et al, (1997) mentioned the difficulties of the above issue, nobody had tried to study a comprehensive training measure instrument like this. The importance of defining and measuring a reaction factor, related to training efficiency through the identification of training quality dimensions, deals with the fact that people who are responsible for the planning and implementation of a training program to conduct it with the maximum transfer of knowledge, attitudes and skills back to trainees' jobs.

\section{Service quality and training issues in the hospitality industry}

The service nature of the hospitality product sets down how consumption is required to take place. Services are generally described as having three unique attributes-features, specifically: 'intangibility', 'inseparability' and 'heterogeneity' (Lashley and Taylor, 1998; Schneider, 1994). In addition, there is another attribute of services called 'perishability' referring to the fact that services cannot be stored for future sale. Intangibility refers on how the product may only be experienced or participated in instead of owned. Inseparability is a consequence of the way that production and consumption are synchronized due to the significant interaction (points of contact) between producer and consumer. Those points of contact Czeipel, Solomon and Suprenant (1985) had described as 'service encounter', Armistead (1994) as 'service stars' and Carlzon (1987) as 'moments of truth'. Heterogeneity means that it is difficult for service organizations to standardize the many 'moments of truth' coming from a typical service encounter. Moreover Clements and Josiam (1995: p.15) note how "damaging an unsuccessful 'moment of truth' can be in the hospitality industry". More measured and less dogmatic accounts of the service encounter are regarded to recognize a number of elements that pose several issues for organizations. This is a particular issue of quality assurance where "the consumer finds it difficult to isolate service quality from the quality of the service provider" (Enderwick, 1992: p.139). 
Tourism and Hospitality Management, Vol. 15, No. 1, pp. 61-72, 2009

I. Valachis, E. Christou, M. Sigala, L. Maroudas: DEVELOPING HUMAN RESOURCES' SKILLS

In this vein, Gronroos in 1984 (p. 38) suggested a framework "whereby two types of quality were distinguished: the technical quality and functional quality". In other words, what the consumer receives as a result of his interactions with a service firm and the way that the service is provided. In addition to the above, Gronroos in 1988 defined another five factors of service quality. Namely, professionalism and skills; reputation and credibility; behavior and attitudes; accessibility and flexibility; and reliability and trustworthiness. The professionalism and skills identified are being familiarized more as service outcome while the other four factors as process dominated. Additionally, a distinction of four dimensions of service quality was recommend by Edvardsson, Thomasson and Ovretveit (1994), which are the technical quality, the integrative quality, the functional quality, and the outcome quality. In another work, Mels, Boshoff and Nel (1997) identified two particular determinant factors that service quality could be defined, the functional and the technical quality, in line with Gronroos' research findings. Relative to the above distinctions in service quality, the scale developed by Parasuraman, Zeithaml and Berry $(1985 ; 1988 ; 1991)$ and called SERVQUAL consisted of five principal components of service quality; the Tangibles; Reliability; Responsiveness; Assurance; and Empathy. Due to the significance of their research, this scale has been replicated across different kind of services, with the unique nature of the hospitality industry to offer great research opportunities for various SERVQUAL tests. For example, Saleh and Ryan in 1991 examined the scale in hotels premises by following SERVQUAL rational and they identified five dimensions (conviviality, tangibles, reassurance, avoiding criticism and empathy) that did not confirm the SERVQUAL dimensions. The study of Getty and Thompson (1994), again in the hotel industry, reached the same conclusion with the Saleh and Ryan (1991) research (SERVQUAL dimensions were not fully met). Following once more the SERVQUAL rational they developed a scale called LODGSERV constituted of three dimensions (tangibility, reliability and contact).

In 1997, Ekinci and Riley (1997: p.163) compared the above scales in a resort hotel sample and their results were that "both scales fail to replicate the proposed dimensions and to provide content validity in this specific application". In 1991, Knutson, Stevens, Wullaert and Patton replicated SERVQUAL in hotels and motels and further verified LODGSERV. Moreover, Johns and Tyas (1996) replicated SERVQUAL in the fast-food sector resulting that all of the six dimensions identified by Parasuraman et al (1991) were verified in the outcome of their research. In a relevant survey Mei, Dean and White (1999) aimed at identifying the most predictive dimension of overall service quality in three to five stars hotels by using an adapted version of the SERVQUAL scale, namely the HOLSERV. According to their findings there are three significant dimensions in the hospitality industry (employees, tangibles and reliability); they also argued that "the employees' dimension emerged as the best predictor of overall service quality, hence effective training of employees is a prerequisite for sustaining high service quality.

A study by Johns and Lee-Ross (1997: p.351-352) on hotel services identified that in the service context "services differ in the proportions of tangibles they contain. It would be reasonable to hypothesize that the importance of tangible aspects is higher in customer experiences such as hotel services, which contain a high proportion of clearly differentiated tangible components". In reference with Gronroos (1988) and 
Tourism and Hospitality Management, Vol. 15, No. 1, pp. 61-72, 2009

I. Valachis, E. Christou, M. Sigala, L. Maroudas: DEVELOPING HUMAN RESOURCES' SKILLS

Parasuraman et al (1991) models, the professionalism and the skill of Gronroos' (1988) service quality determinations' and the tangibles and the reliability of Parasuraman et al (1991) service quality determinations' items can be part of a process-development or outcome-result in the hospitality industry strongly dependant on the skills and competencies of the human resources.

As far as the concept of training, it includes all formal learning actions, which may perhaps, or not lead to qualifications and possibly will be obtained at any time in a working line of business. Training becomes perceptible from some authors as costly (Cheng $\kappa \alpha_{1} \mathrm{Ho}, 2001$ ) since the problem has to do with the fact that that hardly the $10 \%$ of cost for the training correspond in the transfer of knowledge in the working environment (Georgenson, 1982). Also, Patrick (1992) claimed that the greater part of training is unable to be transferred in terms of work.

The deficiencies in research regarding the evaluation of training have as result that only $15 \%$ of enterprises try to evaluate the transfer of training (Haywood, 1992). Thus, the evaluation of transfer constitutes a chance for research from the moment that the human resources executives will need more than never to prove that their investments on training have as result either the improvement of output or the financial benefits. The skills and the knowledge that are acquired through the training process should lead to visible changes both to behavioral and working terms (Caravanglia, 1993).

According to the need for improving the criteria and methods of evaluation regarding the transfer of training, Goldstein (1982) proposed that the research should define variables capable to predict positive transfer. The research of Baldwin and Fold (1989) regarding the transfer of training reveals the existence of gaps between the relative scientific knowledge. This deals with the training inputs such as the characteristics of trainees, the planning of training session and the working environment and the relations between those.

\section{RESEARCH METHODOLOGY}

The first step in the development of any scale is to construct a conceptual specification of the construct being scaled (Churchill, 1979). The conceptual framework of this research was derived from the studies of Kirkpatrik (1959) regarding training evaluation criteria; Ajzen's (1991) theory of planned behavior; the model of training and transfer of Baldwin and Fold (1989) and Parasurman's, Zeithaml's, and Berry's (1985) service quality dimensions and a service quality measure instrument.

The research was developed in two phases. At the first phase the scales were developed, while at the second phase the extended instrument of the training quality, which developed by the trainees' point of view, were tested. Although different guidelines were tested to develop the scale (Churchill, 1979; Rossiter, 2002; Ulaga, and Eggert, 2001; Gerbing, and Anderson, 1988; Tepper Tian, Bearden, and Hunter, 2001; Brotheridge and Lee, 2003; Diamantopoulos, and Souchon, 1999; DeVellis, 1991), the steps employed in constructing the scale provided by Hinkin, Tracey, and Enz (1997). 
Tourism and Hospitality Management, Vol. 15, No. 1, pp. 61-72, 2009

I. Valachis, E. Christou, M. Sigala, L. Maroudas: DEVELOPING HUMAN RESOURCES' SKILLS ...

This guide of developing measurement instruments judged as the most proper due to the fact that referred directly to the hospitality industry and provides clear and helpful steps for developing such a kind of scale, like in the case of Hei-Lin Chu and Murrmann (2006), that they developed a hospitality emotional labor scale, following the same guideline.

\section{FIRST PHASE}

Due to the fact that there is no any other scale to assess training quality, the first phase deals with the development of such a measurement scale. The research is conducted through the use of questionnaires. As mentioned above, although there is a number of scale development instruments, the process that is used by this research is suggested by Hinkin, et al. (1997).

According to the first step that deals with the item generation and the items creation, this research is emphasized on issues of reliability and validity, because, as Hinkin et al. (1997) stated, reduces the likelihoods for methodological problems that probably would controversy the final results. According to DeVellis (1991), the ideal size of the item pool should be four times larger than the final scale, or as small as $50 \%$ larger than the final scale. To generate a large item pool, two sources were used to generate scale items: the existing literature and focus groups. As far as the items generation is concerned, eighth educators and four employees of the hospitality and tourism industry were examined through interviews. Even if the items generated were somewhat redundant, DeVellis (1991) indicated that having multiple and redundant items is important since items' irrelevant idiosyncrasies will cancel out during the scale purification process. Consequently, considerable redundancy in the item pool is desired when developing a new scale.

Next, the qualitative methodology required for words or concepts that defined to be grouped into classes or categories. This process successively led to nine categories of determinant factors/dimensions. These nine categories/factors were correspondently named: Applicability, Consistency, Enjoyment, Interaction, Touchable, Homogeneity, Environment, Politeness, and Responsibility.

An inductive approach was used to concentrate the specific information for training. The subjective choice of the researcher as far as the titles and the names of the nine dimensions are concerned, directed from the results of the interviews' concept analysis. The final step on the qualitative process was to develop the attributes or the items that support or explain further each dimension of the training quality (Hinkin, et al., 1997). The items that were created were based on interviewees' comments and the understanding of the scientific content by the researcher. Sixty-eight items were created for the nine dimensions of training quality.

As far as the content adequacy assessment is concerned, the second step, fortyfive students of the Department of Tourism Management of the School of Management and Economics of the Technological Educational Institute of Thessaloniki completed the corresponding questionnaire. Regarding the analysis of the students' answers, the 
Tourism and Hospitality Management, Vol. 15, No. 1, pp. 61-72, 2009

I. Valachis, E. Christou, M. Sigala, L. Maroudas: DEVELOPING HUMAN RESOURCES’ SKILLS ...

choice of the items is based on an acceptable agreement index of .60 (Hinkin et al., 1997). Using the same criteria, 35 items were defined (51\%). This process led to thirtysix items for the nine dimensions of the training quality.

Regarding the third step, the thirty-six items that were developed in the $2^{\text {nd }}$ step were incorporated in a questionnaire and each item was presented in two ways. One, in a training expectation, on the first part, and, in a perception way for the reality that presented during the training session, on the second part of the questionnaire. The developed questionnaire was delivered to five training programmes in the broad area of Macedonia (Greece) and Cyprus in academic subjects related to tourism and hospitality (Katerini, Thessaloniki, Kilkis, Cyprus, Halkidkiki). The researcher with the trainers' assistance delivered the questionnaires at the end of each training session. Due to the fact that this stage of the research was a step on the scale development and not a real test of the final instrument, the perceptions and the expectations were tested synchronously at the end of the training season (Hinkin et al., 1997). From the 182 trainees that attended the sessions, 155 of the questionnaires were able for analysis (85.6\%). According to Guadagnoli and Velicer (1988), in the most of the researches, the sample size of the 150 observations are adequate for the achievement of the exact solution in an exploratory factor analysis since the correlations between items are strong.

After finishing data collection, it is important and crucial to evaluate the items' efficiency for the determination whether compose adequately the scale (Siardos, 2004). The factor analysis is repeated for the GAP measurement, for a perceptions and expectations measurement of training quality, individually. In this final stage of factor analysis for the GAP measurement of the training quality from the trainees' point of view, the Measure of Sampling Adequacy (MSA) and the Bartlett's test of sphericity were used to ensure that the data had inherent sufficient correlations to perform the scale. The MSA index was .617 and the Bartlett's test of sphericity rejected the null hypotheses that the matrix of elements was an identity matrix, proposing that existed important correlations between at least certain variables, which justified the use of the scale. The first factor analysis resulted in a 9-factor solution, which explained $62.80 \%$ of variance. To attain a further meaningful solution, items were deleted if they loaded regularly heavily on more than one factor, and their loadings were smaller than .55 , in consideration of the small sample size (Hair et al., 1998). After the factor analysis, 26 items were found to determine the nine dimensions of training quality.

Regarding factor analysis for the measurement of trainees' perceptions, the MSA index was .791 and Bartlett's test of sphericity rejected the null hypotheses that the matrix of elements was an identity matrix, proposing that important correlations between at least certain variables exist, which justified the use of the scale. The first factor analysis resulted in a 9-factor solution, which explained $73.28 \%$ of variance. After the factor analysis, 23 items were found to determine the nine dimensions of training quality from the trainees' point of view.

As far as the measurement of trainees' expectations factor analysis is concerned, the MSA index was .802 and Bartlett's test of sphericity rejected the null hypotheses that the matrix of elements was an identity matrix. The first factor analysis 
Tourism and Hospitality Management, Vol. 15, No. 1, pp. 61-72, 2009

I. Valachis, E. Christou, M. Sigala, L. Maroudas: DEVELOPING HUMAN RESOURCES’ SKILLS ...

resulted in a 9-factor solution, which explained $71.65 \%$ of variance and 24 items were found to determine the nine dimensions of training quality.

At the fifth step and by examining firstly the internal consistency results, the overall Chronbach alpha score for all of the items for the GAP measurement scale of training quality was .7903 (high). The dimension of homogeneity had the higher internal consistency score and the dimension of enjoyment had the lower. Regarding the internal consistency scores for the measurement of trainees' perceptions, the overall Chronbach alpha score for all of the items was .8650 (very high). The dimension of interaction had the higher internal consistency score and the dimension of touchable had the lower. As far as the internal consistency scores for the measurement of trainees' expectations, the overall Chronbach alpha score for all of the items was .7998 (high). The dimension of interaction had the higher internal consistency score and the dimension of politeness had the lower. A test of Internal Consistency Assessment took place as well regarding the three items that comprise the scale to measure the construct of intention of the trainees to use the skills and knowledge they obtained through the training sessions back to their jobs. The Chronbach alpha score was very high (.9340).

Although both consist a good base for Construct Validity, the further test of them was necessary according to the sixth step. The scales that were developed until this point were further tasted for Construct Validity and internal consistency (Hinkin et al., 1997).

\section{SECOND PHASE}

At the second phase of the research, the exploratory factor analysis for the scales that developed in the first phase was replicated. The scales that were developed during the distillation process in the first phase were integrated in an instrument that delivered to 239 tourism and hospitality trainees in 8 training sessions in Central Macedonia, Greece. Before start testing the three null hypothesis, the factor analysis was repeated for the three scales for the further analysis and distillation of the dimensions that were defined in the first phase.

After the second factor analysis for:

* the GAP measurement of the training quality from the trainees' point of view, the MSA index was .785 and the Bartlett's test of sphericity rejected the null hypotheses that the matrix of elements was an identity matrix, proposing that existed important correlations between at least certain variables exist, which justified the use of the scale. The first factor analysis resulted in a 6-factor solution, which explained $66.8 \%$ of variance and 16 items in total were defined the GAP measurement of training quality scale. The dimensions of Touchable, Politeness and Enjoyment that were appeared in the first phase they rejected in the second phase during the replication of factor analysis for the GAP measurement of training quality. Then, the reliabilities of the construct indicator for each dimension were tested with the use of Cronbach Alpha and the overall reliability for the six dimensions that compose the GAP measurement of training quality was .7986. 
Tourism and Hospitality Management, Vol. 15, No. 1, pp. 61-72, 2009

I. Valachis, E. Christou, M. Sigala, L. Maroudas: DEVELOPING HUMAN RESOURCES' SKILLS ...

* the measurement of trainees' perceptions, the MSA index was .813 and the Bartlett's test of sphericity rejected the null hypotheses as in the previous measurement. The first factor analysis resulted in a 7-factor solution, which explained $67.9 \%$ of variance 15 items in total defined the measurement of trainees' perceptions of training quality scale. The dimensions of Politeness and Enjoyment that were appeared in the first phase, they couldn't succeed to appear during the replication of factor analysis for the measurement of trainees' perceptions of training quality in the second phase. The overall reliability for the seven dimensions was .8789 .

* the measurement of trainees' expectations, the MSA index was .698, and Bartlett's test of sphericity rejected the null hypotheses, which justified the use of the scale. The first factor analysis resulted in a 6-factor solution, which explained $61.5 \%$ of variance and 13 items in total defined the measurement of trainees' expectations of training quality scale. The dimensions of Politeness, Environment and Enjoyment they rejected after the replication of factor analysis. The overall reliability for the six dimensions that compose the perceptions Measurement of training quality was .7678.

\section{RESEARCH HYPOTHESIS}

First Null Hypotheses (1): The dimensions that define training quality are similar to the service quality dimensions (tangibles, reliability, responsiveness, assurance, and empathy). The research approached inductively and didn't try to plan and present the training quality dimensions in order to reflect those of service quality dimensions. On the contrary, the qualitative research was opened to appoint the unique training quality items, and the titles and definitions of the final dimensions, were resulted from the research data illustration.

As far as the contrast between service quality and training quality, the service quality scale was found to have five dimensions whereas the training quality scale was found to have six dimensions with the measurement of GAP model, seven according to the measurement of perceptions and six in reference with measurement of expectations. To the extent that the training quality measured by:

$>$ the GAP: three out of six dimensions are related with those of service quality,

$>$ the measurement of perceptions: four out of seven dimensions are equalized with those of service quality, and

$>$ the measurement of expectations: three out of six dimensions are matched with those of service quality.

Accordingly, four out of five dimensions of service quality matched with two or three dimensions of the three scales. Since:

- four out of seven $(57.14 \%)$ dimensions of training quality that were found according to the measurement of perceptions; three out of six found with the GAP measurement $(50 \%)$; and three out of six found with the expectations measurement $(50 \%)$ of training quality, and 
Tourism and Hospitality Management, Vol. 15, No. 1, pp. 61-72, 2009

I. Valachis, E. Christou, M. Sigala, L. Maroudas: DEVELOPING HUMAN RESOURCES' SKILLS ...

- four out of five $(80 \%)$ dimensions of service quality come through the training quality dimensions according to the measurement of perceptions and three out of five $(60 \%)$ come through the measurement of expectations and GAP measurement,

a greater homogeneity between the dimensions of service quality and those of the scale of the measurement of perceptions of training quality rather than between the GAP and expectations measurement scales, so the null hypothesis was rejected and the first hypotheses was confirmed.

Second Null Hypotheses (2): The correlation of the GAP result, in all dimensions, is not equal with the correlations of the measurement of perceptions or expectations in all dimensions of the total quality of training. A correlation measure it was the most proper statistical test in order to define if the three variables were linked (Bora-Senda and Moediades, 1997; Moore, Duckworth, and Sclove, 2002; Phagan, 2002; Gnardelis, 2006). In this case, the correlation between training quality of the GAP measurement scale and the general training quality was compared with the scale of the measurement of perceptions and expectations with the same, general, training quality. The simple correlation analysis produced a correlation matrix that defines:

$>$ a statistically significant positive correlation (.365) between training quality as determinate through the mean of GAP scores for each dimension of training quality and the general training quality that indicated by the trainees,

a statistically significant positive correlation (.567) between training quality as determinate through the mean of the measurement of perceptions scores for each dimension of training quality and the general training quality that was indicated by the trainees, and

$>$ a statistically significant positive correlation (.411) between training quality as determinate through the mean of the measurement expectations scores for each dimension of training quality and the general training quality that was indicated by the trainees.

Accordingly, the second research question was confirmed due the fact that the correlation between the three measures of training quality and the general trainees' training quality estimation wasn't equal. Due to the fact that the correlation coefficient for the perceptions measurement was higher from the other two correlation coefficients, it was evidence to prove that the training quality that was defined through the measurement of perceptions associated more with the general training quality than the measurement of the GAP or expectations. This result supported the validity of the training quality measurement scale as defined through the seven dimensions of training quality.

Third Hypotheses (3): The greater the trainees perception regarding the quality of training, the greater their intention to transfer the skills and knowledge they obtained during their training in terms of working environment. Simple correlation coefficient was used to test hypothesis on the .05 level (H0: $\rho=0, \mathrm{H} 2: \rho>0$ ). The hierarchical nature of this research dictated that the measurement method that would have found to be the most highly correlated with overall training quality via the testing of second hypothesis would be used to test the third hypothesis. Consequently, training quality as defined through the measurement of perceptions correlated with the scores of 
Tourism and Hospitality Management, Vol. 15, No. 1, pp. 61-72, 2009

I. Valachis, E. Christou, M. Sigala, L. Maroudas: DEVELOPING HUMAN RESOURCES' SKILLS ...

the three items of the intention to transfer training concept. The scores indicated a statistically positive correlation .568 (level .01) between training quality through the measurement of perceptions of trainees in a seven dimensions scale and the intention to use training. As a result, the third hypotheses was confirmed.

\section{Discussion}

The overall purpose of this study was to develop an instrument that emerged as a result from the scale determination process. The development and validity process of the scale were presented in detail. Two studies were conducted to establish and confirm scale unidimensionality, reliability and validity. The first study with 155 hospitality and tourism trainees was conducted with the purpose of item purification. The results of the first study derived a 31 item scale. The first phase included the development of the items that further examined the measurement of GAP, expectations and perception on training quality, individually. To further examine the scale's property, a second study was conducted and data collected from 239 hospitality and tourism trainees. The test of second phase further filters the scales while support the three null hypothesis. As a result from this research, a scale of fifteen items and seven dimensions that were based on the measurement of trainees' perceptions were developed. These are the following:

\section{Interaction}

1. Training session involves active learning.

2. Training session features small group work.

3. Trainees are active participants in training.

\section{Consistency}

4. Trainer is knowledgeable about the field of study.

5. Training session is developed by people who have done the trainee's job.

6. Training session is well-planned.

\section{Homogeneity}

7. Trainees come from the same professional sector

8. Training session refers to trainees with the same development prospects

\section{Applicability}

9. Training session directly related to trainees' jobs.

10. Training session presents a realistic picture of the job.

\section{Responsibility}

11. Trainees understand the rewards of implementing training.

12. Training session includes a test to evaluate what trainees have learnt

\section{Touchable}

13. The written material of the training session is professionally prepared

14. The training classroom provides the natural comfort for the trainees

\section{Environment}

15. Trainees feel comfortable during the training session

This research considered a new framework for training assessment. Based on the fact that training is a service, the theories of service quality; training; education; human resource development; and planned behavior consisted the basis for the development of a multidimensional model of service quality that could matched on Kirkpatick's (1959) model as the first level or reaction measurement of training effectiveness. 
Tourism and Hospitality Management, Vol. 15, No. 1, pp. 61-72, 2009

I. Valachis, E. Christou, M. Sigala, L. Maroudas: DEVELOPING HUMAN RESOURCES’ SKILLS ...

In reference with the theoretical applications of the research on the one hand, the scale that was result of this research had presented positive validity and consistency scores in the primary stages of the research. Possibly, the further research will confirm these primary results facing as well as the generalization issue of the scale in the various types of training programs. This research expands the range of the knowledge regarding training with the integration of new data adopted from various scientific fields. Furthermore, it contests the methodology used by the researchers who used one or two measures of training quality through the use of SERVQUAL items. As resulted from this research, to measure expectations; perceptions; and perceptions minus expectations it produced different scores and different dimensions which derived from those measurements.

On the other hand, the direct practical contribution of this research is the understanding of the qualitative principal components of a training program that potentially will improve the quality of the training programs that offered from the organizations. Even without the practical instrument's use, every constructor or educator of a training program can use these seven principal components as a framework/template for qualitative training programs. According to the research findings, any training program that adopts these training quality's seven principal components/dimensions will result in greater training transfer in the working environment.

As well as, it could be used to evaluate the employees' perceptions regarding the organization's training programme annually or in a particular manner. Moreover, the scale could be used to assess the success of a training programme regarding each individual dimension. A low score individually in a dimension could be used as an index for better efforts to achieve the desirable results.

\section{BIBLIOGRAPHY}

Ajzen, I. (1991) The Theory of Planned Behavior. Organizational Behaviour and Human Decision Processes, Vol. 50, pp. 179-211

Alliger, G. M., Tannenaum, S. I., Bennett, Jr. W., Traver, H., and Shotland, A. (1997) The meta-analysis of the relations among training criteria. Personnel Psychology, Vol.50, pp.341-358.

Baldwin, T. and Ford, K. (1988) Transfer of training: A review and directions for future research. Personnel Psychology, Vol. 41, pp. 63-105

Bora-Senda, H. and Moediades, Ch. (1997) Applied statistics: multiply regration, despretion analysis, timeseries. Thessaloniki: Ziti, $2^{\text {nd }}$ ed. (in Greek)

Brotheridge, C., and Lee, R. (2003) Development and validation of the emotional labor scale. Journal of Occupational and Organizational Psychology, Vol.76, pp. 365-379

Carlzon, J. (1987). Moments of Truth. Cambridge, Mass: Ballinger Publishing.

Czeipel, J., Solomon, M. \& Suprenant, T. (1985). The Service Encounter: Managing Employee/Customer Interaction in Service Businesses. Lexington, Mass: D. C. Heath.

Churchill Jr., G. A. (1979) A paradigm for developing better measures of marketing constructs. Journal of Marketing Research, Vol.16, pp.64-73.

DeVellis, R. F. (1991) Scale development: Theory and application. Newbury Park, CA: Sage.

Diamantopoulos, A. and Souchon, A.L. (1999) Measuring Export Information Use: Scale Development and Validation. Journal of Business Reseacrh, Vol.46, pp.1-14

Eddie, W.L., Cheng, Ho. and Danny, C.K. (2004) A review of transfer of training studies in the past decade. Personnel Review, Vol 13, No.3, pp. 102-118.

Edvardsson B., Thomasson B. \& Ovretveit J. (1994). Quality in Service. Maidenhead: McGraw Hill

Enderwick, P. (1992). The scale and scope of service multinationals. In P. Buckley \& M. Casson (eds.), Multinational Enterprises in the World Economy - Essays in Honour of John Dunning (pp. 134152). Aldershot: Edward Elgar. 
Tourism and Hospitality Management, Vol. 15, No. 1, pp. 61-72, 2009

I. Valachis, E. Christou, M. Sigala, L. Maroudas: DEVELOPING HUMAN RESOURCES' SKILLS ...

Ekinci, Y. \& Riley, M. (1997). Examination of the SERVQUAL and LODGSERV scales performance in the case of holiday makers perception of resort hotel service quality: a pilot study. In N. Hemmington (ed.), Proceedings of the Sixth Annual Council for Hospitality Management

Education (CHME) Research Conference (pp.163-185). Oxford: Oxford Brookes University.

Georgenson, D. L. (1982) The problem of transfer calls for partnership. Training and Development Journal, Vol.36, No.1, pp.75-78.

Gerbing, D. W. and J. C. Anderson (1988) An Updated Paradigm for Scale Development Incorporating Dimensionality and Its Assessment. Journal of Marketing Research, Vol.25, (May), pp.186-92.

Getty, J. \&Thompson, K. (1994). A procedure for scaling perceptions of lodging quality. Hospitality Research Journal, 18(2): 75-96.

Gnardelis, Ch. (2006) Data analysis with SPSS 14.0 for Windows. Athens: Papazisi

Goldstein, I. L. (1993) Training in Organizations. Belmont: Brooks/Cole Publishing Company.

Gronroos, C. (1984). A service quality model and its marketing implications. European Journal of Marketing, 18(4): 36-44.

Gronroos, C. (1988). Service quality: The six criteria of good perceived service quality. Review of business, 9(3): $10-13$

Guadagnoli, E. and Velicer, W. F. (1988) Relation of sample size to the stability of component patterns. Psychological Bulletin, Vol.103, pp. 265-275.

Haywood, K. M. (1992) Effective training: Toward a strategic approach. Cornell Hotel and Restaurant Administration Quarterly, Vol.33, No.6, pp.43-52.

Hinkin, T. R., Tracey, J. B., and Enz, C. A. (1997). Scale construction: Developing reliable and valid measurement instruments. Journal of Hospitality and Tourism Research, Vol.21, No.1, pp.100-120.

Hei-Lin Chu, K., and Murrmann, S,K. (2006) Development and validation of the hospitality emotional labor scale. Tourism Management, Vol, 27, pp.1181-1191

Jameson, S.M. (2000). Recruitment and training in small firms. Journal of European Industrial Training, 24(1): 43-49.

Johns, N. \& Tyas, P. (1996). Use of service quality gap theory to differentiate between foodservice outlets. The Service Industries Journal, 16(3): 321-346.

Johns, N. \& Lee-Ross D. (1997). A study of service quality in small hotels and guesthouses, Progress in Tourism \& Hospitality Research, 3: 351-363.

Kirkpatrick, D. L. (1959) Techniques for evaluating training programs. Journal of the American Society of Training Directors, Vol.13, No.59, pp.3-9.

Kirkpatrick, D. L. (1979) Techniques for evaluating training programs. Training and Development Journal, Vol.33, No.6, pp.78-92.

Lashley, C. \& Taylor, S. (1998). Hospitality retail operations types and styles in the management of human resources. Journal of Retailing and Consumer Services, 5(3): 153-165.

Mei, A.W., Dean, A.M. \& White, C.J. (1999). Analysing service quality in the hospitality industry. Managing Service Quality, 9(2):136-143.

Ulaga, W., Eggert, A. (2001) Developing a Standard Scale of Relationship Value in Business Markets. Proceedings of the 17th IMP conference, Oslo.

Parasuraman, A., Zeithaml, V. A., and Berry, L. L. (1985) A conceptual model of service quality and its implications for future research. Journal of Marketing, Vol.49, pp.41-50.

Patrick, J. (1992) Training: Research and Practice. London: Academic Press

Rossiter, J.R. (2002) The C-OAR-SE procedure for scale development in marketing. International Journal of Research in Marketing, Vol.19, Vol.305-335.

Siardos, G. (2004) Multivariable methods for statistical analysis, $1^{\text {st }}$ Part: Relations' expansion between variable, $3^{\text {rd }}$ ed. Thessaloniki: Ziti (in Greek)

Schneider, B. (1994). Human resource management: a service perspective. International Journal of Service Industry Management, 5(1): 64-76.

Saleh, F. \& Ryan, C. (1991). Analysing service quality in the hospitality industry using the SERVQUAL model. The Service Industries Journal, 11(3): 324-343.

Tepper Tian, K., W. O. Bearden, and G. Hunter (2001) Consumers' Need for Uniqueness: Scale Development and Validation. Journal of Consumer Research, Vol.28, pp.50-66. 